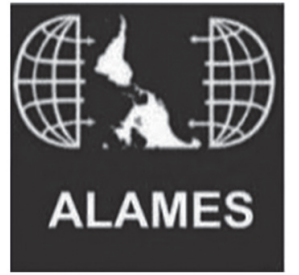

Asociación Latinoamericana de Medicina Social

${ }^{\star}$ Astana Kazajstan octubre 2018.

\section{Declaración de ALAMES frente al intento de absorber la APS en la, muy cuestionada, Cobertura Universal de Salud (UHC)*}

Asociación Latinoamericana de Medicina Social1

DOI: $10.1590 / 0103-110420185129$

La autoridad de la OMS y mas aun de UNICEF para convocar una Conferencia de esta naturaleza será proporcional a su capacidad de autocrítica y de una razonable explicación sobre el fracaso de

la meta SPT200O
1 Asociación

Latinoamericana de Medicina Social - Buenos Aires, Argentina.
Aun cuando insuficiente la APS fue adquiriendo desde el año 78 una progresiva legitimidad por haber sido apropiada por cientos de miles de trabajadores de salud que se desempeñaban y se desempeñan fuera de las paredes de los hospitales y por las agresiones recibidas primero de parte de la Fundación Rockefeller (APS selectiva) de UNICEF, del Banco Mundial (Invertir en Salud) y así pudimos constatar que la APS no condujo necesariamente a la Meta Salud para Todos (2000) y que los organismos multilaterales recuperaron recién su potencial a los 25 años (OPS, 2003) y a los 30 años (OMS, 2008) no solo con una velada reivindicación sino incluso con una ampliación de su agenda y contenidos.

Halfdan Mahler ex director de la OMS y cofundador del Movimiento por la Salud de los Pueblos, Movimiento con el que ALAMES mantiene relaciones formales desde hace una década, solicitó permanecer alerta y denunció en el 2007 específicamente a UNICEF y a los "cocodrilos conceptuales" que quieren reducir los alcances de una APS comprensiva.

En efecto, el intento de absorber lo que hay construido y se ha acumulado tras el concepto de Atención primaria de la Salud por parte de los privatizadores abiertos o encubiertos de la salud quedó metafóricamente expuesto por Halfdan Mahler que como: "presidente honorario de la conferencia de Buenos Aires [2007] en su discurso inaugural afirmó que: 'estamos hasta el cuello en el fango verbal contra los cocodrilos conceptuales, que nos quieren comer de un solo bocado'. Y señaló: 'Mi profunda esperanza es que esta reunión técnica y política nos proporcione municiones para eliminar los cocodrilos conceptuales que rondan el entorno sanitario'"'.

En consecuencia, declaramos

i. Frente al punto 3 de los supuestos del borrador que menciona: La declaración enmarca el papel de la APS dentro de los esfuerzos nacionales para lograr la cobertura universal de salud (UHC por sus siglas en inglés); y lo expuesto en el título: "Poner la salud pública y la atención primaria en el centro de la UHC" 
1. No acordamos con la cobertura universal de salud sistemáticamente apoyado en la falacia "sin dificultades financieras" que lejos de apoyar la gratuidad de los servicios públicos por la vía de sistemas nacionales impulsa la generación de seguros públicos que en todo el mundo se ha visto como el mecanismo que claramente facilita la expansión de los servicios privados. Una objeción que ha llevado a los ministros de salud de la UNASUR en un contexto de mayoría de gobiernos populares, a forzar una posición matizada de la CUS por parte de la OPS conocida como Salud Universal (cobertura más acceso universal garantizado).

2. En consecuencia, consideramos que enmarcar la APS en la Cobertura Universal en Salud (UHC) constituye un retroceso en comparación con haberla definida como "la" estrategia para alcanzar la meta de Salud para Todos: una meta que puede interpretarse como una forma de enunciar el derecho a la salud concepto claramente mucho más amplio y abarcativo que el de cobertura financiera.

3. Por consiguiente, no aceptamos colocar a la APS (reducida nuevamente a un primer nivel de atención) ni a la Salud Pública en el centro de la CUS. Es mas bien la cobertura sanitaria apenas uno de los rasgos de una salud pública no positivista que articula con una APS Comprensiva y entendida como una agenda de reforma de todo el sector como ya se insinuaba en la Declaración de Alma Ata.

ii. Frente a la declaración: "Tenemos más probabilidades de tener éxito que nunca".

1. Las condiciones políticas no podrían ser peores y ciertamente lo son comparadas con 1978 en que una distensión de la guerra fría habilitó cierto grado de conversaciones de desarme (Salt II) las alianzas de países exportadores de materias primas mejoraban las relaciones de intercambio (OPEP) conocido en el momento como Nuevo Orden Económico Internacional, Existía un fuerte movimiento de países no alineados y Estados Unidos atravesaba un breve período demócrata con apelo a Derechos Humanos (J. Carter, expresada en la presencia de E. Kennedy en Alma Ata desde entonces referente demócrata de todos los intentos de reforma en salud de los EE.UU.)

2. Las actuales condiciones indican que 40 años después un Estados Unidos desquiciado económicamente intenta prevalecer por su poderío militar desarmando bloques de alianzas históricos, los países europeos oscilan entre gobiernos de derecha y social demócratas, que no modifican en nada su orientación política neoliberal liderado por una Unión Europea que opera mas como un aparato de captura que como un bloque regional.

3. La concentración de la riqueza no solo se ha incrementado, sino que se ha privatizado, haciendo que un millar de personas posean individualmente capitales superiores al PBI de países enteros. Un fenómeno facilitado por los paraísos fiscales que independizó a las empresas de sus compromisos fiscales.

4. Nuevas formas de burlar las reglas de juego de la democracia permiten que países enteros pasen a control de empresarios por medio de operaciones mediáticas y judiciales enmarcadas en el constructo "postverdad" haciendo que cualquier intento de desalinearse de Washington devenga en un delito no excarcelable.

5. En definitivamente tenemos menos probabilidades de tener éxito que nunca y reescribir la declaración y reabrir el debate sobre un consenso que se sostuvo por 40 años solo puede hacernos retroceder.

Cuarenta años después la APS ha devenido 
un atractivo bocado para "los cocodrilos conceptuales” y será un deber de todos que se queden con las ganas.

iii. Frente a diversos párrafos convocando a la participación del sector privado: $\boldsymbol{i}$.

“...creando responsabilidad social tanto del sector público como del privado", ii. "Mejoraremos la gobernanza participativa de los sistemas de salud, incluida la participación y la regulación del sector privado", iii. Actuaremos inmediatamente sobre esta Declaración en coordinación con la Organización Mundial de la Salud y el Fondo de las Naciones Unidas para la Infancia, comprometiéndonos con... la sociedad civil y el sector privado... para expandir y apoyar este movimiento.

Resulta imprescindible comprender 40 años después que buena parte de la inviabilidad de "salud para todos" ha provenido fundamentalmente del Complejo Médico Industrial y de los agentes económicos que utilizando estrategias de monopolio en segmentos específicos del mercado de salud han establecido precios abusivos, lucran en uno de los mercados más imperfectos que existen a partir de claras asimetrías de información y se han conjurado hoy en absorber, incluso los sistemas de seguridad social europea. Convocar al sector privado trasnacionalizado, hoy constituye una complicidad y/o una ingenuidad inaceptable para una Conferencia Mundial, una acción que se puede simplemente describir como la notable idea de poner al zorro a cargo del gallinero para que no se las coma.
En definitiva, en una alianza estratégica con el Movimiento por la Salud de los Pueblos denuncia el intento de "reescribir" la Declaración de Alma Ata en condiciones de claro retroceso de los procesos democráticos, de concentración del ingreso y de una desregulación del capital sin precedentes, que solo puede lograr consensos sobre retrocesos.

En definitiva, ALAMES propone enfáticamente que: la Conferencia de Astana, se comprometa con el derecho a la salud, que reafirme en un todo la declaración de la Conferencia de Alma Ata y que el producto de sus discusiones se incorporen como nuevos aportes a su avance frente a los nuevos desafíos del Siglo XXI.

La declaración de Alma Ata, aunque insuficiente, continuará siendo una hoja de ruta razonable para cientos de miles de trabajadores de salud y de comunidades que en todo el mundo han hecho "contacto" con los servicios formales de salud de la mano de esta estrategia; recordando que la Atención Primaria de la Salud fue pensada y diseñada no como un fin en sí mismo, sino como un medio -no el único- de construir el derecho a la salud para todos los ciudadanos y ciudadanas del mundo. Si sus componentes mas políticos como participación social, interculturalidad, protagonismo y abogacía de los trabajadores de salud, intersectorialidad se alinean en un movimiento latinoamericano y mundial por la construcción y defensa del derecho a la salud, recién allí aceptaremos que las condiciones para volver a escribir la declaración de Alma Ata han llegado.

\section{Referência}

1. La Nacion. Acusaciones sobre fracasos em salud. 2007 [acesso em 2018 out 15]. Disponível em: https://www.lanacion.com.ar/934361-acusaciones-sobre-fracasos-en-salud. 